\title{
Transient Analysis of the Self Excited Induction Generator Subjected to Grid Disturbances
}

\author{
Malika Imadouchene \\ Mouloud Mammeri University of Tizi-Ouzou, Algeria \\ email: malika.imadouchene@g.enp.edu.dz
}

\begin{abstract}
The present paper analyzes the consequences of short grid voltages interruptions on gridconnected self-induction generator, particularly, on the currents and electromagnetic torque of the generator. These effects depend on several variables such as the phase difference between the grid voltages and those of the generator, the magnitude of the grid voltage and the generator currents at the instant of reconnection to the grid. The approach has been used for studying the effects of these grid disturbances on the self-excited induction generator; is a numerical approach. In the numerical approach, which is based on the dynamic $d$-q model of the induction generator, the effect of magnetic saturation is accurately accounted for. This numerical model has been validated by experimental measurements taken from an induction generator test bench. The analysis focuses on the amplitudes of the peaks of the currents and torque during short interruptions especially at the reconnection of the grid voltage. The results obtained from the numerical model are compared to the measured ones.
\end{abstract}

Keywords: self-excited induction generator, modelling, analytical model, numerical model, saturation, transient analysis, wind energy

Copyright $\odot 2015$ Institute of Advanced Engineering and Science. All rights reserved.

\section{Introduction}

Many types of generators have been used and proposed to convert wind and hydro power into electrical energy. The three-phase induction generator is well suited for small scale wind power applications both in grid connected mode and in self-excited stand-alone mode. This generator offers the significant advantage of allowing variable speed operation [1-3]. However, the self-excited induction generator is unable to produce reactive power and thus requires a separate excitation device such as capacitor bank. Alternatively, the induction generator could be used in isolated load or grid connected operating mode [5-6]. Two significant disadvantages arise when induction generators are used in grid connected mode. First, there is high demand of reactive power by the induction generator. Second, there is a large transient current due to direct connection of the induction generator to the grid [6-7]. Indeed, one of the operating events producing major transient interaction between an induction generator and the local grid is the connection process. This is particularly noticeable in fixed-speed turbines when equipped with squirrel cage induction generators (SCIGs). Moreover, the disturbances caused by the reconnection to the grid may be more troublesome when they are recurring and random in their nature. This is often the case after voltage sag occurring at network level. Voltage sags are currently a matter of concern because they can give rise to a number of problems in the generator itself and the supplied equipment depending on their particular sensitivity [8-12]. In the scientific literature the recent grid code revisions, the ride-through capability of wind turbines connected to the electricity grid are reported and discussed by several authors [13-14]. In this paper, the behaviour of the self-excited induction generator following a short interruption of the grid voltage is studied. The study pointed out the parameters which affect the magnitudes of current and torque peaks. The potential consequences on the self-excited induction generator due to the fast reconnection of the grid are discussed. The study is carried out on a $3,5 \mathrm{~kW}$ selfexcited induction generator. Measured and computed results are presented and discussed.

\section{Induction Generator Modelling}

The voltages equations expressed in the stator reference frame are given by [3]: 


$$
\left\{\begin{array}{l}
v_{d s}=r_{s} \cdot i_{d s}+l_{s} \frac{d i_{d s}}{d t}+\frac{d \phi_{m d}}{d t} \\
v_{q s}=r_{s} \cdot i_{q s}+l_{s} \frac{d i_{q s}}{d t}+\frac{d \phi_{m q}}{d t} \\
0=r_{r} \cdot i_{d r}+l_{r} \frac{d i_{d r}}{d t}+\frac{d \phi_{m d}}{d t}+\omega_{r} \cdot \phi_{q r} \\
0=r_{r} \cdot i_{q r}+l_{r} \frac{d i_{q r}}{d t}+\frac{d \phi_{m q}}{d t}-\omega_{r} \cdot \phi_{d r}
\end{array}\right.
$$

All rotor quantities and parameters are referred to the stator. The stator and rotor flux linkages may be written as:

$$
\begin{aligned}
& \Phi_{d s}=L_{s} i_{d s}+M i_{d r} \\
& \Phi_{q s}=L_{s} i_{q s}+M i_{q r} \\
& \Phi_{d r}=L_{s} i_{d r}+M i_{d s} \\
& \Phi_{q r}=L_{s} i_{q r}+M i_{q s}
\end{aligned}
$$

The electromagnetic torque is given by:

$$
\Gamma_{e}=\Phi_{d r} i_{q s}-\Phi_{q r} i_{d s}
$$

\subsection{Magnetic Saturation Modelling}

The aim of the present section is to take into account the effect of magnetic saturation in the dynamic model of the induction generator [3]. Only the main flux path is supposed to be affected by the saturation, the leakage flux is assumed to be constant [3]. The saturation effect is approximated by using an analytical model of the magnetizing curve. Figure 1 shows the measured magnetizing flux as a function of the magnetizing current. The mathematical approximation is obtained by using the arc tangent function; the following equation gives the relation between flux and magnetizing current:

$$
\Phi_{m}=0.63 \arctan \left(0 . \Phi I_{m}\right)
$$

The measurements of magnetizing flux are carried out through a no-load experimental test at synchronous speed. The measured magnetizing curve and its mathematical approximation are illustrated by the Figure 1 below.

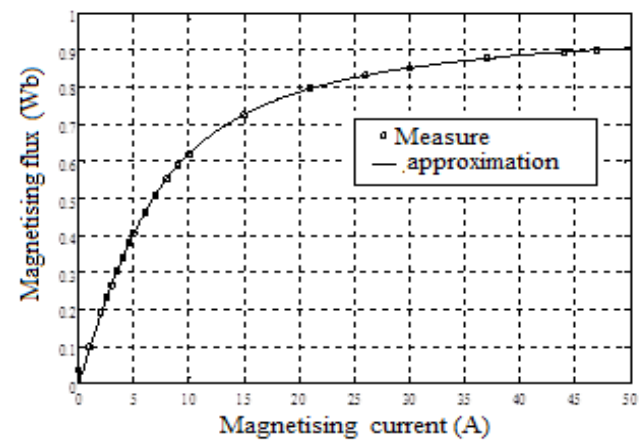

Figure 1. Magnetizing flux versus magnetizing current

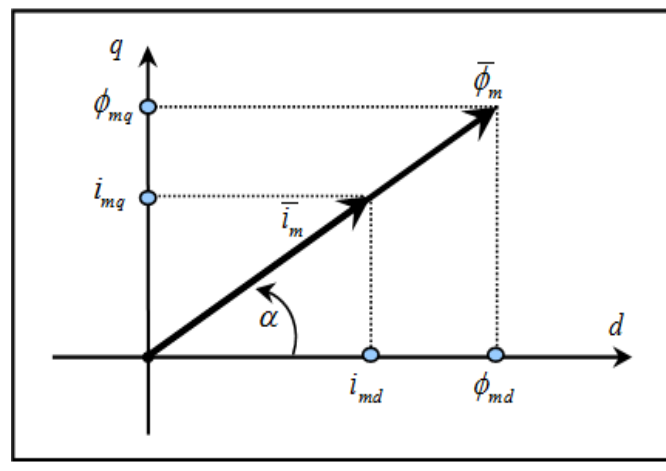

Figure 2. Magnetizing flux and current phases in $d-q$ axis representation 
The derivative of the magnetizing flux is expressed by:

$$
\frac{d \Phi_{m}}{d t}=e^{j \alpha} \frac{d \Phi_{m}}{d t}+j e^{j \alpha} \Phi_{m} \frac{d \alpha}{d t}
$$

With:

$$
\left\{\begin{array}{c}
\bar{\Phi}_{m}=\Phi_{m} e^{j \alpha} \\
\bar{i}_{m}=i_{m} e^{j \alpha}
\end{array}\right.
$$

By using the followings relations given from Figure 2.

$$
I_{m d}=I_{m} \operatorname{co\alpha } ; I_{m q}=I_{m} \sin \alpha ; \Phi_{m d}=\Phi_{m} \cos \alpha ; \Phi_{m q}=\Phi_{m} \sin \alpha ; \alpha=\operatorname{arctg} \frac{\operatorname{Imq}}{I m d}
$$

We obtain the expressions of speed vector flux and magnetizing current derivative by:

$$
\begin{aligned}
& \frac{d \alpha}{d t}=\frac{1}{I_{m}^{2}}\left(i_{m d} \frac{d i_{m q}}{d t}-i_{m q} \frac{d i_{m d}}{d t}\right) \\
& \frac{d I_{m}}{d t}=\frac{1}{I_{m}}\left(i_{m d} \frac{d i_{m d}}{d t}+i_{m q} \frac{d i_{m q}}{d t}\right)
\end{aligned}
$$

By putting the flux in terms of magnetizing inductances in both axis $d$ and $q$ we get:

$$
\frac{d \bar{\Phi}_{m}}{d t}=L_{m d} \frac{d i_{m d}}{d t}+L_{d q} \frac{d i_{m q}}{d t}+j\left(L_{m q} \frac{d i_{m q}}{d t}+L_{d q} \frac{d i_{m d}}{d t}\right)
$$

Where,

$$
\left\{\begin{array}{c}
L_{d q}=\left(M_{d y}-M_{s t}\right) \frac{i_{m d} i_{m q}}{I_{m}^{2}} \\
L_{m d}=M_{d y}-\left(M_{d y}-M_{s t}\right)\left(\frac{i_{m q}}{i_{m d}}\right)^{2}=M_{d y}-L_{d q} \frac{i_{m q}}{i_{m d}} \\
L_{m q}=M_{d y}-\left(M_{d y}-M_{s t}\right)\left(\frac{i_{m d}}{i_{m q}}\right)^{2}=M_{d y}-L_{d q} \frac{i_{m d}}{i_{m q}}
\end{array}\right.
$$

With:

$$
M_{s t}=\frac{\Phi_{m}}{I_{m}} \quad \text { et } \quad M_{d y}=\frac{d \Phi_{m}}{d I_{m}}
$$

$M_{s t}$ and $M_{d y}$ are respectively static inductance and dynamic inductance. The Figure 3 and 4 show the static and dynamic inductances obtained by calculation. 


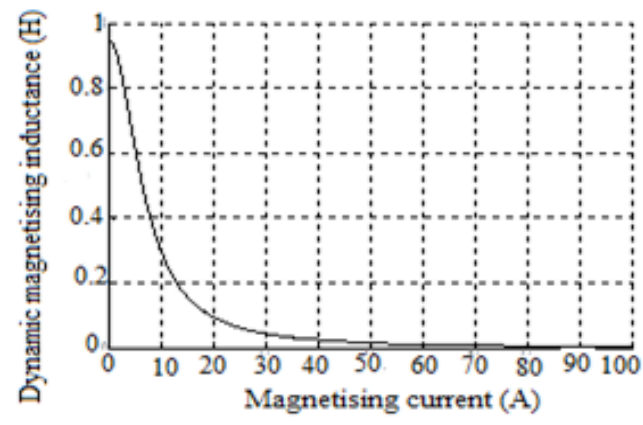

Figure 3. Dynamic magnetising inductance

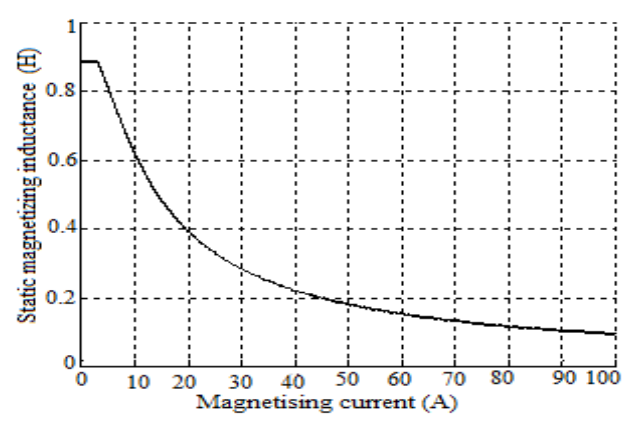

Figure 4. Static magnetising inductance

These curves represented in Figure 3 and 4 are obtained from the curve of Figure 1.

Finally the system of Equation (1) can be written in both axes $d$ and $q$ by:

$$
\left\{\begin{array}{l}
v_{d s}=R_{1} i_{d s}+L_{\sigma 1} \frac{d i_{d s}}{d t}+L_{m d} \frac{d i_{m d}}{d t}+L_{q d} \frac{d i_{m q}}{d t} \\
v_{q s}=R_{1} i_{q s}+L_{\sigma 1} \frac{d i_{q s}}{d t}+L_{m q} \frac{d i_{m q}}{d t}+L_{d q} \frac{d i_{m d}}{d t} \\
v_{d r}^{\prime}=R_{2}^{\prime} i_{d r}^{\prime}+L_{\sigma 2}^{\prime} \frac{d i_{d r}^{\prime}}{d t}+L_{m d} \frac{d i_{m d}}{d t}+L_{q d} \frac{d i_{m q}}{d t}+\omega_{r}\left(L_{\sigma 2}^{\prime} i_{q r}^{\prime}+M_{s t} i_{m q}\right) \\
v_{q r}^{\prime}=R_{2}^{\prime} i_{q r}^{\prime}+L_{\sigma 2}^{\prime} \frac{d i_{q r}^{\prime}}{d t}+L_{m q} \frac{d i_{m q}}{d t}+L_{d q} \frac{d i_{m d}}{d t}-\omega_{r}\left(L_{\sigma 2}^{\prime} i_{d r}^{\prime}+M_{s t} i_{m d}\right)
\end{array}\right.
$$

The electromagnetic torque is given by:

$$
\Gamma e=\Phi_{d r} I_{q s}-\Phi_{q r} I_{d s}
$$

\subsection{Observation of the Self-excitation Process}

The self-excitation phenomenon is governed by the voltage equations below:

$$
\left\{\begin{array}{l}
\frac{d V_{d s}}{d t}=\frac{1}{C} i d s \\
\frac{d V_{q s}}{d t}=\frac{1}{C} i_{q s}
\end{array}\right.
$$

Before the connection to the power grid, the voltage is built up across the stator terminals of the induction generator. Appropriate values for the self-excitation capacitors and the rotor drive speed are elaborately chosen. The experimental test was carried out by using a $3,5 \mathrm{~kW}$ induction generator at no load. Figure 5 and 6 shows respectively, the measured and simulated stator voltage and stator current.

Figure 5 and 6 show that the voltage and the current increase up to a limit value which is determined by the saturation. Measured and computed results illustrated by these figures are in good agreement. This coherence between simulation and experimentation confirms the validity of the saturated developed model. 


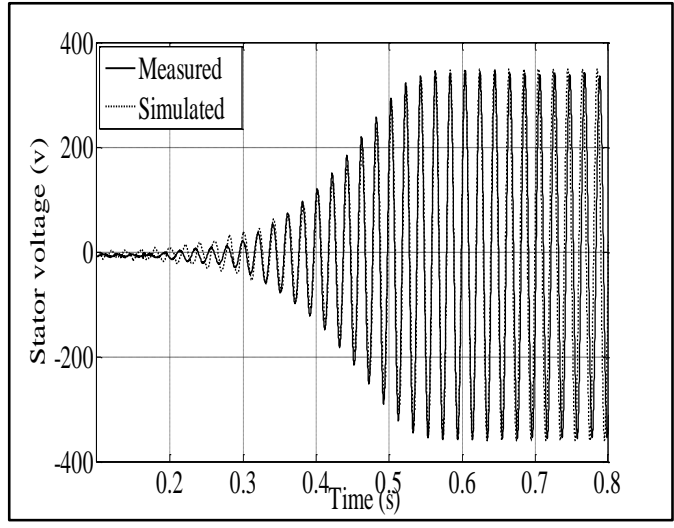

Figure 5. Measured and simulated stator voltage $\mathrm{N}=1500$ rpm $\mathrm{C}=180 \mu \mathrm{F}$

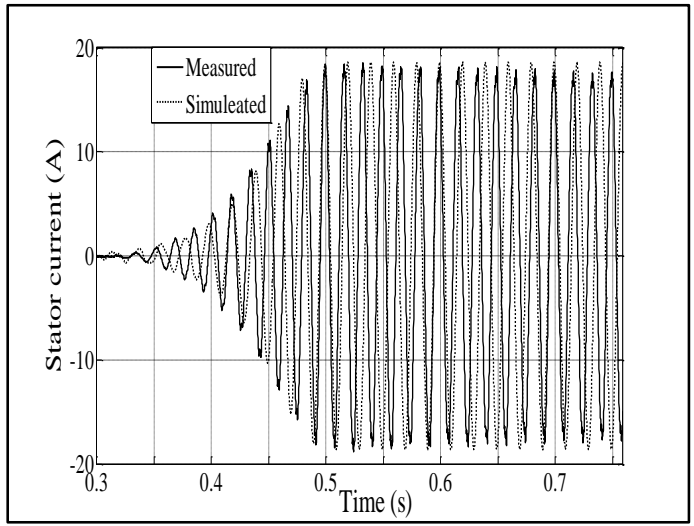

Figure 6. Measured and simulated stator current $\mathrm{N}=1500$ rpm $\mathrm{C}=180 \mu \mathrm{F}$

\section{Currents and Torque Magnitudes at the Reconnection to the Grid}

Usually a fixed speed generator is connected to the network via an AC / AC dimmer. The Figure 6 a shows the principle of this connection a schematic way.

The procedure of the connection can be divided in the following step.

1) Starting the driving motor to the synchronous speed of the generator

2) When the self-excitation is reached the induction voltage build up to the final value

3) Once the steady state is reached the self-excited induction generator (SIEG) is switched on the grid throughout the soft starter by decreasing firing angle of thyristor within a specific law.

4) After soft starting procedure is completed, each line triacs is by passed by a mechanical contactor as show in following Figure 7 below.

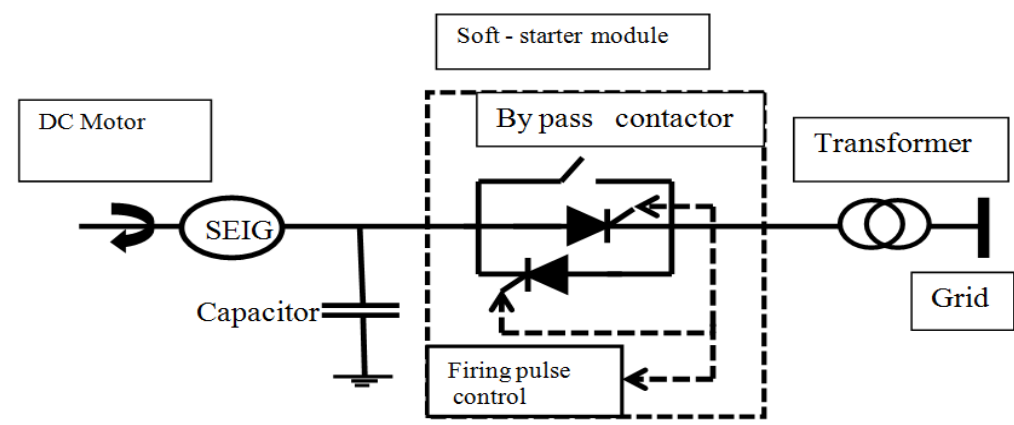

Figure 7. Single line diagram of the Self-excited induction generator using an AC/AC converter

A soft starter is basically an AC/AC converter where for firing angles smaller than $5 \square / 6$ rad, the relationship between the firing angle and the controlled voltage and its variation is no linear.

\subsection{Procedure of Experimental Test}

Momentary short interruptions may occur at any time during the grid exploitation [2, 6]. They are due to transient phenomena such as faults and their durations are so small that the protection circuit cannot be activated. Sometimes their effects are very important and may cause damage to connected devices. In the present section we focus on the maximum values that could take the generator stator and rotor currents during a short disconnection of the grid voltage [7].

To reproduce a grid voltage short interruption we use an experimental test bench whose schematic is shown in Figure 8. The SEIG is driven at synchronous speed by a DC motor, with 
capacitors banc connected at its stator terminals. The circuit breaker $\mathrm{K}$ is used to connect/disconnect the SEIG from the grid; this is used to reproduce the momentary interruptions of grid voltage it is equivalent to the by-pass contactor. The induction voltage and grid voltage have the same value in the test bench laboratory, then the transformer does not exist.

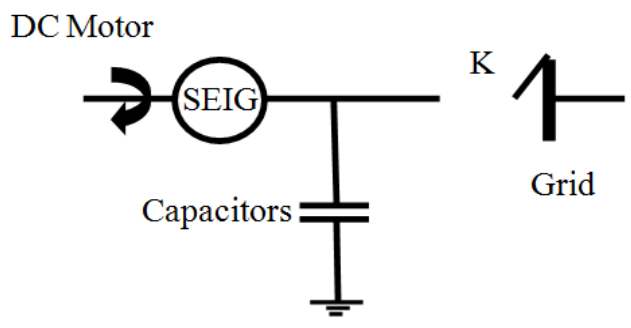

Figure 8. Single line diagram of experimental test bench

The computation of the peak values of the stator and rotor currents is performed using Matlab software. Figure 9 reproduces the single line circuit of the momentary short interruption.

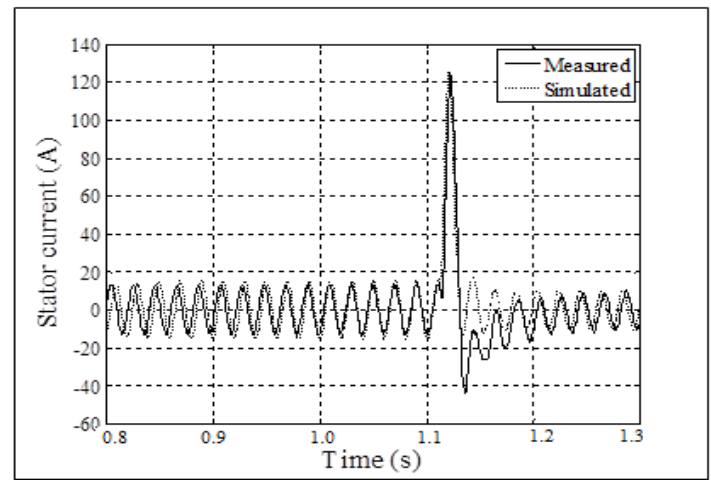

Figure 10. Experimental and simulated stator current with a positive peak following a reconnection of grid voltage

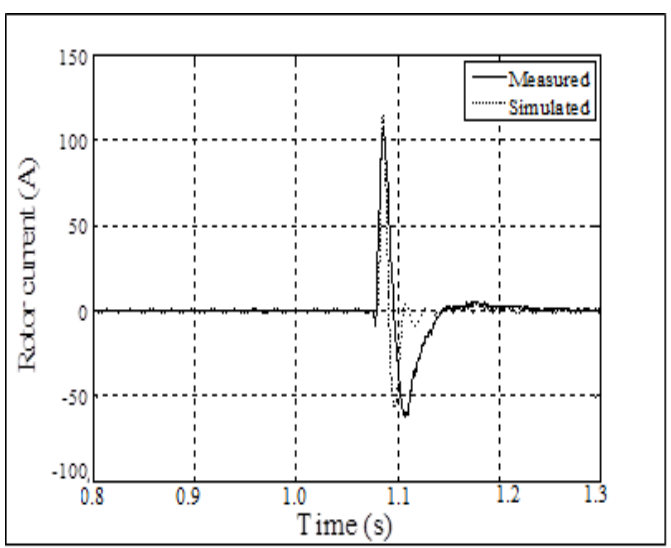

Figure 12. Experimental and simulated rotor current with positive peak following a reconnection of grid voltage

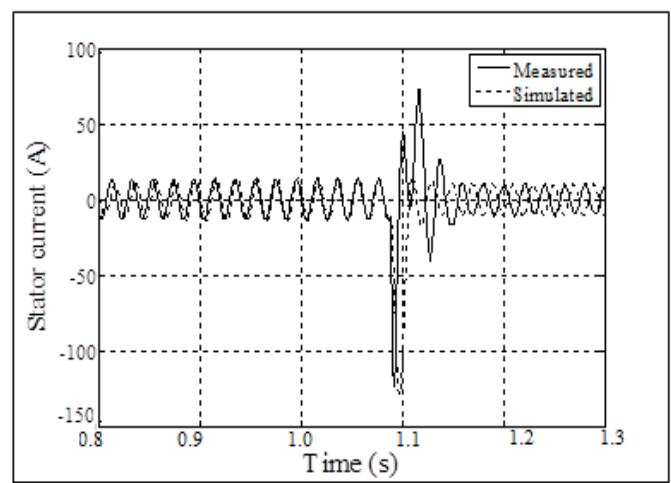

Figure 11. Experimental and simulated stator current with a negative peak following a reconnection of grid voltage

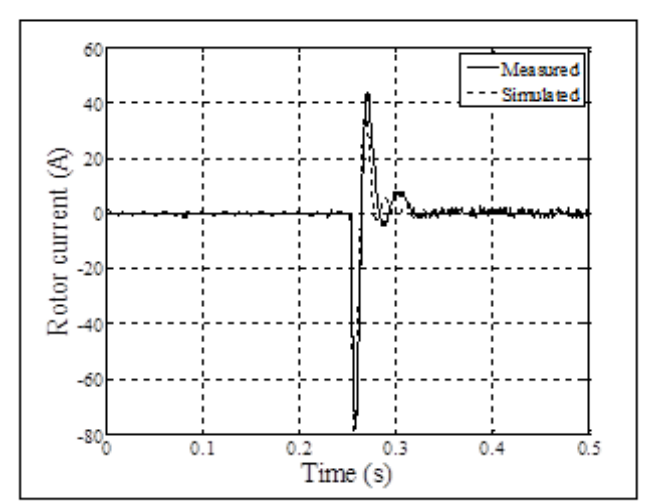

Figure 13. Experimental and simulated rotor current with negative peak following a reconnection of grid voltage 
From Figure 10,11, 12 and 13, it appears that the magnitudes of the stator and rotor currents reach very high values which exceed several times their nominal values. The stator current reach 12 times the rated value (Figure 12) and the rotor current reach 10 times the rated value. These values are excessive.

\subsection{Generalization of Simulation Results}

Momentary short interruptions of the grid voltage are complex because of their randomness. In the previous section it was reported that the peak currents depend on several parameters, such as the shift angle between grid and induction generator voltages, and the moment of reconnection to grid [7]. In simulation it is easy to choose the time of reconnection to the grid, but in practice this variable is random. The grid reconnects to the generator once the fault is cleared. In the present section our aim is to investigate the limit of the peak current and to show under what conditions this limit value can occur. For this, simulation is carried out for several shift angles between the grid and the induction generator voltages, and for several moments of the reconnection. The figures below show the obtained results.

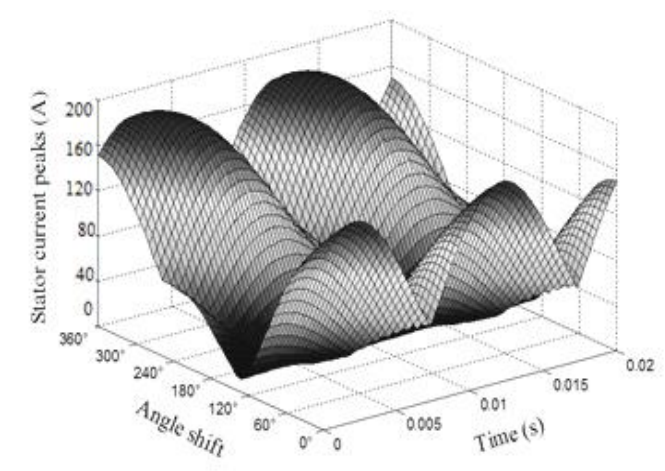

Figure 14. Simulated stator current following a reconnection of grid voltage to the generator

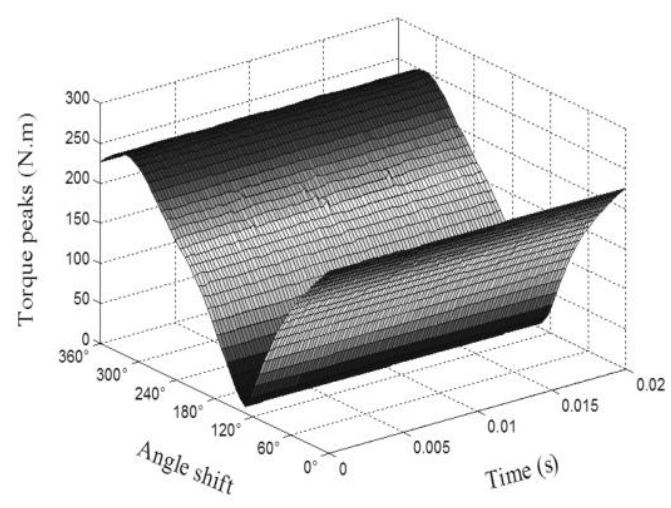

Figure 16. Simulated torque peaks following a reconnection of grid voltage to the generator

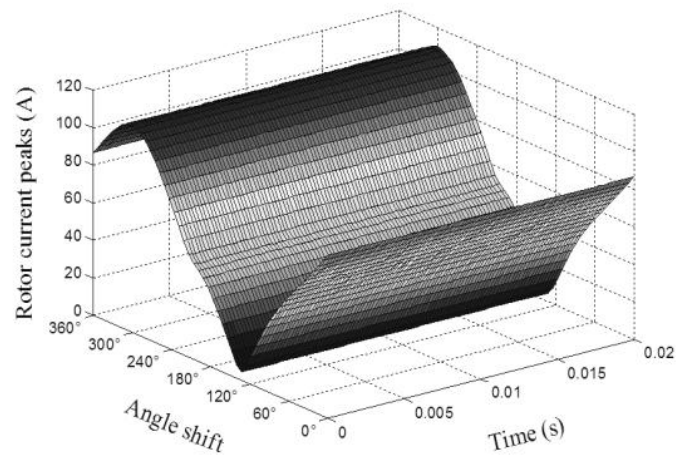

Figure 15. Simulated rotor current following a reconnection of grid voltage to the generator

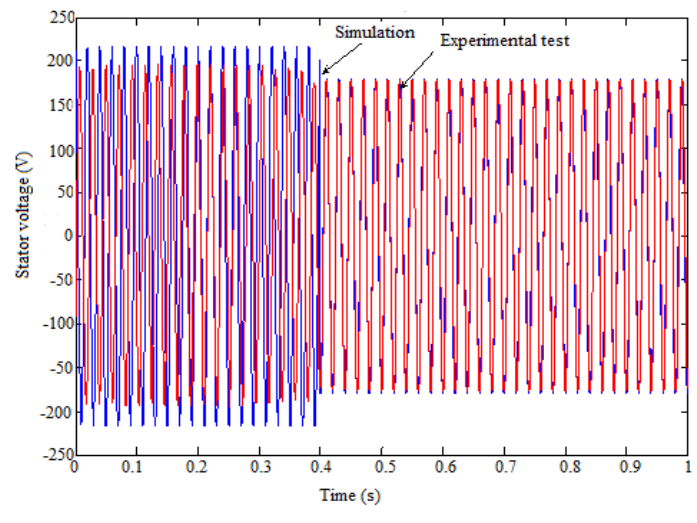

Figure 17. Stator voltage at the moment of the reconnection to the grid voltage

From these Figure 14, 15 we note that the peak of both stator and rotor current can reach 16 times of the rated current. These denote the transient severity of currents if the appropriate conditions are satisfied (angle shift and time of reconnection). These excessive values of the currents can cause damage to the induction generator. On the Figure 16 we see the excessive value of the electromagnetic torque. This value exceeds 15 times of rated torque and can cause damage to the mechanical transmission. The Figure 17 show the stator voltage simulated and measured at the time of the reconnection the grid to the induction generator. 


\section{Conclusion}

The grid reconnection to self-excited induction generator after short interruptions is a complex phenomenon which depends on several parameters. The phase-shift between voltages and currents of the induction generator and the phase-shift between the voltages of the induction generator ant that of the grid voltage is among the most influencing. The magnitudes of the transient currents and the torque are closely related to the values of these parameters. The magnitudes of the transient currents and torque depend also on the initial conditions of induction generator variables at the time of reconnection to the grid. This is because during the grid interruption the induction generator goes into no-load self-excited operating mode. Several experimental tests were conducted and reproduced in simulation. From all these results it was noticed that the highest peak current is obtained when the voltages of the induction generator and grid are in opposition shift angle. In the stator as well as in the rotor windings, the magnitude of the peak current can reach 15 to 20 times the rated value.

\section{References}

[1] Li Wang, Ching-Chung Tsao. Performance analyses of a three-phase induction generator connected to a utility grid. Power Engineering Society Winter Meeting, 2001, IEEE. 2001; 3: 1398-1402.

[2] Orabi M, Ninomiya T. Operating performance of induction generator connected to utility grid during grid separation. Industrial Electronics, 2004 IEEE International Symposium. 2004; 2: 1315-1323.

[3] P KOVACS. On the Theory of Cylindrical Rotor AC Machines, Including Main Flux Saturation. IEEE Transactions on Power Apparatus and Systems. 1984; 103(4): 754-761.

[4] Petersson A, Thiringer T, Harnefors L, Petru T. Modeling and experimental verification of grid interaction of a DFIG wind turbine. Energy Conversion, IEEE Transaction. 2005; 20(4): 878-886.

[5] Joshi D, Sandhu KS. Soni MK. Constant voltage constant frequency operation for a self- excited induction generator. Energy Conversion, IEEE Transactions. 2006; 21(1): 228-234.

[6] Jsc Htsui. Magnitude, Amplitude and Frequencies of Induction-Motor Air-Gap Transient Torque through Simultaneous Reclosing with or without Capacitors. IEEE Transactions on Power Apparatus and Systems. 1985; 104(6): 1519-1524.

[7] T Senjye, N Sueyoshl, K Uezato, H Fujita. Transient Current Analysis Of Induction Generator For Wind Power Generating System. IEEE PES. 2002; 3: 1647-1652.

[8] B Renders, K De Gussemé, WR Ryckaert, K Stockman, L Vandevelde, MHJ Bollen. Distributed Generation for Mitigating Voltage Dips in Low-Voltage Distribution Grids. IEEE Trans. on Power Delivery. 2008; 23(3): 1581-1588.

[9] M García-Gracia, M Paz Comech, J Sallán, D López-Andía, O Alonso. Voltage dip generator for wind energy systems up to 5 MW. Applied Energy 86. 2009: 565-574.

[10] Yang X. Disturbance assessment in the grid integration of power electronic devices and other nonlinear loads. IEEE Conference Publication. China. 2008: 1-7.

[11] J Lopez, P Sanchis, X Roboam, L Marroyo. Dynamic Behavior of the Doubly Fed Induction Generator During Three-Phase Voltage Dip. IEEE Trans. on Energy Conversion. 2007; 22(3): 709-717.

[12] Palle B, Simoes MG, Farret FA. Dynamic simulation and analysis of parallel self-excited induction generators for islanded wind farm systems. Industry Applications, IEEE Transactions. 2005; 41(4): 1099-1106.

[13] Li Shi-Hua, Tang De-shan. Power grid crises management and empirical research on small disturbance character of power grid. Power and energy engineering Asia-Pacific. 2009: 1-6.

[14] Carolus J Schrijver, Sarah D Mitchell. Disturbances in the US electric grid associated with geomagnetic activity. J.Space Weather Space Clim. 2013; 3: 19-26.

[15] Mohamed EA Farrag, Ghanim A Putrus. Analysis of the Dynamic Performance of Self-Excited Induction generator employed in renewable energy. Energies. 2014; 7: 278-294.

[16] ID Margaris, AD Hansen, P Sorensen, ND Hatziargyriou. Dynamic security issues in autonomous power systems with increasing wind power penetration. Elsevier Electric Power System Research 81. 2011: 880-887.

[17] Radosavljević Jordan, Klimenta Dardan, Jevtić Miroljub. Steady-State Analysis of Parallel-Operated Self-Excited Induction Generators Supplying an Unbalanced Load. Journal of Electrical Engineering. 2012; 63(4): 213-223.

[18] V Sankardoss, SP Sabberwal, K Rajambal. Experimental Design of Capacitance Require For SelfExcitedlnduction Generators. JATIT 15 th. 2015; 45(1).

[19] Ridwan Gunawan, Feri Yusivar, Budiyano Yan. The self-excited Induction generator with observation Magnetizing Characteric in the air gap. International Journal of Power Electronics and Drive System (IJPEDS). 2015; 5(3): 335-365. 